IZA DP No. 10085

Learning and Behavioral Spillovers of Nutritional Information

Prakarsh Singh

July 2016 


\title{
Learning and Behavioral Spillovers of Nutritional Information
}

\author{
Prakarsh Singh \\ Amherst College \\ and IZA
}

\section{Discussion Paper No. 10085 \\ July 2016}

\author{
IZA \\ P.O. Box 7240 \\ 53072 Bonn \\ Germany \\ Phone: +49-228-3894-0 \\ Fax: +49-228-3894-180 \\ E-mail: iza@iza.org
}

\begin{abstract}
Any opinions expressed here are those of the author(s) and not those of IZA. Research published in this series may include views on policy, but the institute itself takes no institutional policy positions. The IZA research network is committed to the IZA Guiding Principles of Research Integrity.

The Institute for the Study of Labor (IZA) in Bonn is a local and virtual international research center and a place of communication between science, politics and business. IZA is an independent nonprofit organization supported by Deutsche Post Foundation. The center is associated with the University of Bonn and offers a stimulating research environment through its international network, workshops and conferences, data service, project support, research visits and doctoral program. IZA engages in (i) original and internationally competitive research in all fields of labor economics, (ii) development of policy concepts, and (iii) dissemination of research results and concepts to the interested public.
\end{abstract}

IZA Discussion Papers often represent preliminary work and are circulated to encourage discussion. Citation of such a paper should account for its provisional character. A revised version may be available directly from the author. 


\section{ABSTRACT}

\section{Learning and Behavioral Spillovers of Nutritional Information*}

This paper provides evidence for informational spillovers within urban slums in Chandigarh, India. I identify three groups, a treatment group, a neighboring spillover group, and a nonadjacent pure control group. Mothers of children (aged 3-6 years) enrolled in government day-care centers are given recipe books in the treatment group to reduce malnutrition in their children. Spillovers to neighboring (untreated) mothers can be through social learning or imitation. Results from a difference-in-differences analysis show that nutritional knowledge measured through a quiz increases among neighboring untreated mothers relative to a control group. Neighboring mothers exhibit learning spillovers, changes in dietary behavior and a reduction in food expenditure regardless of their level of literacy. Spillovers not only raise the cost effectiveness of health information programs but are important to consider when designing an experiment as causal effects of treatments can be attenuated if the spillover group is used as a control group.

JEL Classification: D62, D83, I15, I18, I38

Keywords: $\quad$ spillovers, malnutrition, India

Corresponding author:

Prakarsh Singh

Department of Economics

Amherst College

306B Converse Hall

Amherst MA 01002

USA

E-mail: psingh@amherst.edu

\footnotetext{
* I am grateful to Oriana Bandiera, Jere Behrman, Lena Edlund, Melanie Khamis, Gerard Padró i Miquel, Chih Ming Tan, and Marcos Vera-Hernández for helpful comments, and to Darius Onul and Sam Alpert for research assistance. Thanks also go to seminar participants at Wesleyan University, Indian School of Business and participants at the NEUDC, SEA, LAC-Dev, and Mid-West International Economic Development conferences. I am deeply grateful to the team of enumerators, child care workers, mothers and their children who took part in this project. Finally, this project would not have been possible without co-operation from the staff at the Social Welfare Department, Food and Nutrition Board, and Health Department, Chandigarh. This paper is an output from research funding by the UK Department for International Development (DFID) as part of the iiG, a research programme to study how to improve institutions for pro-poor growth in Africa and South-Asia. The views expressed are not necessarily those of DFID. All errors are my own.
} 


\section{Introduction}

Information dissemination affects knowledge, investments and outcomes and this in turn may have wide-ranging consequences (Jensen, 2010; Reinikka and Svensson, 2005). A change in the information available to a household member may change her knowledge and behavior. However, this may then influence neighboring households. Thus, policy makers should not merely judge the effectiveness of nutritional information campaigns by considering the impact it would have on the direct beneficiaries. Similarly, experimenters need to be careful in deciding the buffer zone between the treatment and control groups. By measuring spillovers, we can evaluate the effectiveness of information campaigns in affecting the health behavior of neighbors. Yet, there is no existing experiment on the extent of learning and behavioral externalities arising out of an informational campaign.

This paper studies the externalities of a treatment involving specific nutritional information to mothers living in urban slums in Chandigarh, India where child malnutrition was very high at 35 percent. The information was imparted to mothers who have their children (aged 3-6 years) enrolled in day care centers or 'Anganwadis' run by the Indian Government under its flagship program, Integrated Child Development Services (ICDS). In each of these centers, there is a child care worker whose role includes advising the mother on child nutrition by making home visits. ${ }^{1}$ The integration of a nutritional campaign into the established system of Anganwadi workers is aided by regular interaction of workers with mothers. Informational intervention in this context aims to decrease the price per calorie for the mother by giving her a list of economical and nutritious recipes and also to reduce malnutrition.

Despite the government program having been in place for 35 years and now spanning over 1.3 million centers, child malnutrition in India is at 37 percent amongst children up to 5 years of age (DHS, 2005). Sen (2005) argues that it is surprising that those at the poverty line do not buy more calories as they could easily afford the calories within their food budget if they had the same food purchasing patterns as those below the poverty line. Less than $1 \%$ of the rural households report lack of food in the state of Punjab, of which Chandigarh is the capital (Deaton and Dreze, 2008). Mothers seem to lack nutritional knowledge, both preventive and curative. A study by the Naandi Foundation has found that $93 \%$ of the mothers are unable to recognize signs of malnutrition (Hungama Report, 2011). Lack of information among mothers is blamed on either general illiteracy or poorly trained government child care workers who are supposed to teach mothers about child nutrition. Sixty five percent of mothers interviewed in this study did not know that the recommended number of meals for children under 6 is 5-6 times a day and their average nutritional quiz score was $25 \%$ less than that of the child care worker. However, if spillover effects are important, then targeting a sub-sample of 
mothers with nutritional information may achieve an increase in the knowledge of neighboring mothers as well making the information dissemination more cost effective. The empirical design of the study recognizes that randomized experiments need to take into account spillovers and simply randomizing without thinking carefully about the control group can bias our estimates. Ours is a controlled non-randomized matched experiment with an exogenous informational treatment.

To identify spillover effects, we compare mothers in the control group to the untreated centers in the informational treatment block both at baseline and endline. The paper finds treatment and spillover effects on learning as measured by a quiz at baseline and endline. There are also interesting results on the mechanisms behind learning. In particular, untreated mothers in the same cluster as treated mothers exhibit changes in (i) nutritional knowledge, (ii) child's dietary intake and (iii) food expenditure. Moreover, direct learning is stronger for literate women but there is learning even for illiterate women in the spillover group, suggesting that some of the learning is verbal. Learning also translates to increased consumption of low price per calorie items and lower food expenditures for both recipe and spillover groups. There are no effects on child weight, but there is an increase in child weight for treated households who own more kitchen assets.

Theoretically, the impact on food expenditure for the spillover group is ambiguous. The recipe book may increase or decrease food expenditure. On the one hand, the mother gets access to cheaper calories, and on the other, she may also decide to make more recipes. The net result will depend on the direct effect through a fall in price per calorie and the indirect effect through a rise in calorie intake. We observe a reduction in food expenditure for the spillover and recipe groups. Nutritional knowledge increases as measured by a multiple-choice quiz administered on the mothers. The quiz has questions based both on and from outside the recipe book. The increase in nutritional knowledge in the spillover group is limited to questions related directly to the informational treatment and appears not to be driven by out-of-book questions.

This paper is related to two strands of research. First, it relates to the nascent literature on spillover effects in public health. Although, it is rare to detect presence of an externality in public health interventions, Miguel and Kremer (2004) showed treatment externalities of deworming on child health. ${ }^{2}$ Peers have been shown to influence use of contraception, menstrual cups and health services (Speizer et. al., 2001; Oster and Thornton, 2012; Deri, 2005). Godlonton and Thornton (2012) incentivized individuals for HIV testing and found positive learning spillovers on their neighbors. Chaudhuri (2009) finds positive spillovers of a health education program for mothers and children in Bangladesh on the health of untreated elderly women in the same household. Thus, the current literature focuses either on learning, behavioral or final health outcomes separately. In this paper, all three 
outcomes are analyzed to tease out mechanisms behind learning. Using learning as well as behavioral outcomes, one can elicit learning through information contagion from mere imitation effects. This may have different policy implications as learning is likely to be long-lasting whereas imitation may be a fad. My results confirm inter-household spillovers on knowledge and food expenditure but not on weight and these effects are similar to those observed in treated households.

Second, information campaigns have been shown to increase the knowledge gap between the informed and the less informed (Tichenor et al., 1970; Kwak, 1999; Nadeau et al., 2008). It is not clear if there would be any impact of the treatment on child health for mothers who cannot read. For example, neighbors or literate husbands can teach uneducated mothers from the recipe book. I find no evidence of intra-household knowledge transfer from a literate father to a treated illiterate mother. Nevertheless, illiterate mothers do show an increase in their knowledge when treated with the recipe book and there also emerge learning spillovers on untreated illiterate mothers in the same slum. This provides suggestive evidence that illiterate treated mothers may learn by asking neighboring mothers while illiterate untreated mothers may increase nutritional knowledge if their neighbors are more informed. My results are consistent with the literature as literate mothers seem to gain more knowledge from the informational treatment. However, learning spillovers act to reduce this informational gap between the treated and the untreated in the same cluster. Neighboring mothers also appear to be more effective than literate fathers in increasing knowledge of an illiterate mother.

The rest of the paper is organized as follows. Section 2 provides the details of the controlled experiment. Section 3 describes the specification and core results. Section 4 reports how spillover effects vary according to mother's literacy. Section 5 checks robustness of the main results through a battery of tests. Section 6 concludes.

\section{Experiment}

\subsection{Background}

Figure 1 depicts the locations of the Anganwadis in the recipe treatment, spillover group and control group centers. Numbers in the map represent the total number of centers within a slum area that are in the recipe treatment, spillover or control groups. As can be seen, there are several slum clusters within a block (6 in each block). Centers within slum clusters in the treatment block are assigned to be either in the recipe or spillover groups. Colors denote the type of treatment or control. The black outline is the administrative boundary of the block. There are 36, 20 and 36 
centers in recipe, spillover and control group respectively, with the recipe and spillover centers being part of one administrative block and the control being part of another as shown. I assess the extent of informational spillovers between mothers sending their children to different Anganwadis but located within the same block.

In December 2009, data on malnutrition rates at the Anganwadi-level was collected from the local Health Department that undertakes weighing of children. ${ }^{3}$ Centers were in groups of slum clusters within a block as shown in the Figure. For every 1000 people living in a slum, the government was supposed to open one additional center. Thus, the number of centers within a slum cluster was proportional to the population in that slum and the number varied although the average was around 10. Centers within a slum cluster tend to be close to each other (by definition, within the same slum area) and cater to the child population living in the same slum.

Each Anganwadi is run by an Anganwadi worker who takes care of children (aged 3-6 years) in a small room from 9 am to $1 \mathrm{pm}$ and is on a fixed salary of Rs. 2000 (\$44.44) per month. There are 28.61 children per center on average (2632 children for 92 centers with one worker per center). Mothers cannot choose between centers as each center is assigned an area from where mothers may either send their children or not. There is no fee paid by mothers. All children who attend the Anganwadi are provided a meal, the distribution of which is supervised by the Anganwadi worker. These servings are of cooked food (e.g. porridge, gruel, etc.) transferred daily from a government approved agency and then distributed into the individual Anganwadis in containers. At the centers, the worker has discretion over its distribution. Workers are also required to hold Monday meetings with the mothers of the children enrolled in the Anganwadi, give tips on nutrition and health and make monthly visits to their homes. Anganwadi workers typically reside in the vicinity of the center. About half of the workers on average have completed high school education. Younger workers have more years of education on average. 80 percent of workers are Hindu and 19 percent identify as Sikh. Workers' age ranges from 20 years to 58 years with the mean being 40 years.

\subsection{Methodology}

One approach in the literature is to conduct a randomized experiment that randomly assigns some centers to the treatment arm, and designates centers close to the treated centers as spillover centers. The challenge is that control centers cannot be close to treatment centers (to avoid spillovers), so the sampling frame needs to be large enough to ensure control centers are not contaminated. This approach is likely to be very costly and in the present context, infeasible. To circumvent this issue, first, we stratify by administrative block and then match on malnutrition rates collected before the baseline. Ideally, there could be more matching variables, but 
there was no additional information available before the baseline. To assure us adequate statistical power, a total of 36 centers were selected to act as control (hereafter, control block) that received no treatment. These 36 centers were randomly selected from all available 67 centers. In a similar manner, 36 centers were selected from all available 56 centers in another block (hereafter, recipe block) to receive the recipe book treatment. This group was selected by an algorithm that matched the aggregate malnutrition average of 36 selected centers out of the 56 available centers in the recipe block to the average malnutrition of the control sample. Note that 20 centers were left untreated in the recipe block and this would constitute the spillover group. ${ }^{4}$

Average malnutrition was chosen as the matching factor as this was the only relevant information available before the baseline at the Anganwadi level. The matching exercise allowed selection of 36 centers to attain optimal power. The untreated centers in the recipe block make up the spillover group and these were surveyed at baseline and endline to study externalities of the recipe treatment within a slum cluster. For this paper, we will focus on the treated and untreated centers in the recipe block, and the pure control block.

It is an empirical question as to how different the recipe treated centers were compared to spillover group. If they were significantly different, we should find significant differences in observables at baseline. If the selected and spillover centers are ex-ante similar, as we might expect given their geographical proximity, the spillover effects of the recipe treatment can be inferred from the changes in outcomes in the unmatched group relative to control using difference-indifferences.

\subsection{Implementation}

To design the recipe book, ten simple cost-effective recipes were selected with the help of the Government's Food and Nutrition Board from the Government's publicly available book on Nutritious Recipes for Complementary Feeding of Young Children. The recipes use only locally available ingredients and were attractively designed and printed in the vernacular (Hindi). Each recipe was rich in calories and could be made at home within a budget of Rs. 4 for 150 grams. ${ }^{5}$ The cost of printing one recipe book was Rs. 10. Each page had boxes at the bottom which mothers were asked to check when they prepared that particular recipe.

The book contained information on ingredients, step-by-step instructions for each recipe and nutritive value (calories, protein, iron and carotene) for each preparation. These were highly recommended by the government nutritionist to reduce calorie-protein malnutrition. While some recipes are almost certainly richer in calories than the usual meals cooked in the area (for example, chidwa laddoo or paushtik burfee provide over $500 \mathrm{kcal}$ in a 100 gram preparation), others are good 
sources of protein (soya chidwa), iron (halwa) or carotene (dalia khichdi). The booklet contained information on ingredients, step-by-step instructions and nutritive value (calories, protein, iron and carotene) for each preparation. The recipes chosen were age and location-appropriate and were supposed to be cost effective in improving both nutrition and caloric deficiencies. It is important to note that Radhakrishna (2006) argues for an increase in the calorie intake of the bottom 30 percent of the population in India and this is especially required for young children suffering from malnutrition. In a similar vein, Mehta et al. (2013) finds that the intake of fats among school-aged children in the Ludhiana district of Punjab is only $55 \%$ of the recommended dose in the urban area. The book also had basic information on hygiene and highlighted food items rich in calories, protein, iron and carotene. The main aims of the recipe book were three-fold: first, reduce malnutrition by teaching mothers calorific and easy-to-make recipes. Second, lower the price per calorie incurred by the mother by giving her a list of cost-effective nutritious recipes and third, to improve the communication between the mother and the child care worker.

A book was distributed at baseline in the center to every mother after filling her questionnaire and quiz. The informational environment is such that the workers know that the mothers are getting the book and the mothers also know that the workers are aware of this fact. The child care worker is supposed to supervise the children in the day care center, advise mothers on child nutrition at the center and also make personalized home visits. At baseline, only 45 percent of the mothers could read but they were given the book even if they could not. Also, 73 percent of the fathers were literate as reported by the mother.

In April 2010, a team of nine enumerators weighed the universe of children present in their centers on digital weighing machines and interviewed mothers of most of these children. ${ }^{6}$ Weights were recorded before the mid-day meal and it was ensured that children were not in heavy clothing. The interviews were taken by calling all mothers to their Anganwadi at specified times. Enumerators collected information on demographics of the household, diet of the child and mother-worker interaction. A quiz was administered to judge the nutritional knowledge of all the mothers and the worker. The multiple-choice quiz for mothers had 5 questions (worth 13 points because of multiple answers per question) that could be answered by reading the recipe book. The next 4 questions (worth 7 points) were "out-ofbook". Mothers in the recipe treatment were provided with the recipe book after they were quizzed, whereas mothers in the spillover or control group did not get the book. Enumerators also noted the previous weight recorded in registers for each child.

A window of 3 months was chosen for the controlled experiment because it is the average time duration between two medical check-ups by the local Health Department. The duration was verified to be sufficient for a grade improvement to 
occur by doctors at the local office of the Health Department, Government of India. The second round of the experiment was conducted in July 2010. The children were weighed again and questionnaires re-administered to mothers. The questionnaire used at endline was the same as the one used at baseline. Surveys for illiterate and literate mothers were carried out by the enumerators who read out each question to mothers.

\subsection{Compliance and attrition}

Table 1 shows the compliance and attrition rates. There were 36 Anganwadis each in the recipe and control groups and the remaining untreated 20 centers from the recipe block formed the spillover group. At baseline and at endline, on average 96 percent of the children weighed also had their mothers quizzed, indicating a high compliance rate. High compliance mitigates the concern that there is a selection bias in certain types of mothers being quizzed and given the recipe book. Moreover, high compliance is observed for all groups addressing the possibility of systematic selection of different types of mothers in different groups and strengthening internal validity. A total of 3038 children were weighed at baseline and a panel of 2632 children were re-weighed at endline in the recipe treatment, spillover and control groups. The attrition rate was 13 percent for the children, which is considered normal as children leave the day-care centers for admission in schools or if the family migrates. Mothers of 2904 children were quizzed at baseline and a panel of 2515 children had their mothers interviewed at endline. All children present in centers were included in the study at baseline (384 children were absent at baseline). In Table A1, the observable characteristics of the attrited sample from baseline show insignificant normalized differences relative to control for almost all relevant variables. ${ }^{7}$ Also, there is no movement of children between centers (even within the same cluster) as the same set of children for each Anganwadi are covered in the two rounds.

\subsection{Summary statistics}

Table 2 lists the summary statistics from the recipe, spillover and control groups as well as the normalized differences between them. We find that in the recipe and spillover groups, the average z-score and malnutrition rates are insignificantly different from the control group. Similarly, the average age of a child is about four years and four months and the mother is just over 28 years old. On average, the household income is slightly lower in the recipe and spillover groups relative to the control at around $\$ 75$ a month. ${ }^{8}$ Also, fridge ownership in the recipe and spillover groups is half of that in the control. Close to 75 percent of all mothers are 
housewives. About 70 percent of the households own a mobile phone, but less than 4 percent own a water filter in the recipe treatment. At baseline, the mother's average nutritional knowledge score as measured by a quiz is 12.4 compared to 15 for the Anganwadi workers. The normalized differences show that on the whole, the observable statistics are very similar across all groups barring ownership of fridge. ${ }^{9}$

In terms of diet, more than 80 percent of the mothers provide milk and green vegetables at least twice a week to their children. However, 50 percent are unable to give their children fruits and only 11 percent give traditional sweets that are rich in calories and less than 10 percent provide non-vegetarian food with a frequency of two times a week. On average, households report spending 52 percent of their income on food.

\section{$3 \quad$ Empirical specification and results}

\subsection{Empirical Specification}

The baseline regression specification for finding learning and spillover effects on learning is as follows:

$$
\begin{aligned}
& q s_{i j t}=\alpha_{0}+\alpha_{1}(\text { post })_{t}+\alpha_{2}{\text { (recipe })_{j}+\alpha_{3}\left(\text { spillover }_{j}+\alpha_{4}(\text { post * }\right.}_{\text {recipe })_{j t}+X_{i j}+\varepsilon_{i j t}} \\
& q s_{i j t} \text { is the quiz score of mother of child } i \text { in Anganwadi } j \text { at time } t \text {. }
\end{aligned}
$$

The variable post is a dummy that is 0 for baseline and 1 for endline. The variable recipe is 1 if the child is in the recipe treatment and 0 otherwise. Similarly, spillover is 1 if the child is in the spillover group (going to an Anganwadi in the treated slum area but where the Anganwadi has not been treated directly) and 0 otherwise. $X_{i j}$ encompasses individual and Anganwadi specific controls. ${ }^{10}$ The individual controls are measured at baseline and include household demographics, kitchen and nonkitchen assets, literacy levels of parents and workers, mother's religion, and satisfaction levels of workers. Specifically, controls include age of the mother, proportion of kitchen assets owned: fridge, water filter, water tap, cooking gas and pressure cooker, proportion of non-kitchen assets owned: mobile, television, scooter, radio and a flush toilet, number of siblings of the child, adult members in household, and the following dummy variables: mother's occupation is housewife, mother's religion is Hindu, if there was grandmother at home, high experienced worker (if experience of the worker is greater than the median experience), literate mother (if the mother can read), literate father, high educated worker (at least till after A-level or end of high school), worker is very satisfied with work, and worker 
is very satisfied with life. Anganwadi specific infrastructure controls included electricity, fan, blackboard, and drinking water. All our main results are robust to inclusion of these conservative controls. The variable post accounts for the natural increase in knowledge in 3 months, all seasonal effects on knowledge, regional shocks in levels of information (through for example, radio and print advertisements on health) and any management changes or unobservables that would impact all groups in the same way. Thus, the control group absorbs any seasonal changes, city-wide economic, political or bureaucratic shocks, weather patterns, city-level festival shocks and also changes because all children who were weighed at baseline are getting older. There are bound to be changes over time in all groups but we need to take account of any changes that cannot be attributed to the treatment. As control is the omitted category, $\alpha_{2}$ is the baseline difference between the recipe group and the control. $\alpha_{3}$ is similarly the baseline difference between the spillover group and the control. If $\alpha_{2}$ and $\alpha_{3}$ are insignificant, it would mean that the treatment and spillover centers are ex-ante similar to the control group on the outcome variable. $\alpha_{4}$ is the difference-in-differences estimate for the direct learning effect and $\alpha_{5}$ is the spillover effect. The standard errors are clustered at the level of a center.

\subsection{Knowledge}

Table 3 shows the spillovers on learning of providing the recipe book. Learning is proxied by a quiz score as measured by a 20 point mother's quiz implemented at baseline and endline. All mothers were interviewed by enumerators. The translation of the multiple-response quiz is pro- vided in Figure A4 in the Appendix. At baseline, mothers in the control group score 12.5 out of 20 (constant term in column 1). Mothers in the recipe and spillover groups show strong learning effects. There is an increase in the quiz score for spillover mothers that is comparatively smaller compared to the increase in the recipe treatment but still high and significant. The quiz contained two sections: a 13 point section that could be answered by reading the recipe book and a general 7 point non-recipe section. That the increase in the spillover group is from the recipe score section (as in the direct treatment) gives further impetus to the mechanism that strong informational learning and spillovers took place because of the recipe book. If the increase in quiz scores was being driven by out-of-book questions, it may have signalled a transmission channel through the workers who were simply paying more visits to the mothers as they had a recipe book.

However, it is possible that the channel of information transmission was workers in the neighboring Anganwadis and not treated mothers. All mothers at endline were asked if they had learnt any new recipes from other mothers in the previous month. I find a $30 \%$ increase in mothers reporting learning a new recipe 
from other mothers in the spillover group relative to control. This is a helpful check to delineate the channel that mothers learnt new recipes from other mothers. This still does not rule out the mechanism that mothers in the spillover groups may get their information through their Anganwadi workers (who talk with workers or mothers from treated Anganwadis). However, I do not observe an increase in the quiz scores of the workers from treated or spillover Anganwadis, implying that treated mothers are likely to be the initiators and the mothers in the vicinity receptors.

Another important mechanism of the type of information transfer can be related to quantity of calories and protein versus the quality of diet making it rich in micronutrients. Both these are important for reducing child malnutrition. In Table A2 (in the Appendix), I construct a quantity and quality score index from the quiz. Quantity score is derived by adding scores on questions (2), (5), and (6) that deal with number of meals, sources of calories and sources of protein. Quality score is derived by summing up scores on questions (3), (4), (7), (8), (9) and (10) that deal with sources of iron, vitamin-A, iodine and calcium among others. This table provides evidence for a significant increase in the quantity and quality scores for the recipe group but only an increase in the quantity score for the spillover group. Even though the difference in their coefficients is not significant, it appears that micronutrient knowledge is less likely to be transmitted to the neighboring mothers as compared to calorie-protein knowledge.

\subsection{Weight}

Table 4 illustrates the results for the final health outcomes: weight, weight-for-age grade (this Indian Association of Pediatrics classification was used in the Anganwadis), z-score based on WHO weight-for-age tables (2006) and malnutrition status (WHO, 2006). We find that there are no spillovers on the weight of the child, her malnutrition grade, z-score or the likelihood of being malnourished. The result is robust to including a vast array of controls. This shows that on average providing recipe books to mothers has no direct impact on the weight of her child or the child of the same slum-dwelling mothers. Nevertheless, we observe that the weight has increased by 275 grams on average in the control group and also the recipe and spillover groups (column (1)). However, WHO (1983) reports that the expected normal increase for a 4 year old over three months is 500 grams. This implies a significant increase in malnutrition of 3.6 percentage points in all groups (including the control group). The results are similar if other control variables are added (columns (5)-(8)). ${ }^{11}$

This increase in malnutrition for all groups could be due to at least two reasons that are common to all groups. First, the seasonality effect of going from dry and hot April at baseline to a rainier July at endline. According to the 
Meteorological survey of India, Chandigarh received $0 \mathrm{~mm}$ of rainfall in April 2010 and $458.8 \mathrm{~mm}$ in July 2010 . There is a large literature on seasonality in weights for young children. For example, Brown et al. (1982) uses longitudinal field studies of the growth, dietary intake, and morbidity from infectious diseases of children between 6 and 60 months of age in two rural villages of Bangladesh to assess that there are significant seasonal fluctuations in growth, nutritional status, and the prevalence of malnutrition. The paper notes that the periods of greatest nutritional deficit generally occurred during the monsoon or rainy season and persisted until the subsequent harvest period. Miller et al. (2013) and Kobayashi and Kobayashi (2006) also find seasonal variations in weight consistent with Brown et al. (1982). There is also some recent evidence on seasonality of eggs and cereal consumption in India (Karthikeyan and Nedunchezhian, 2014; Oldiges, 2012). More- over, the health environment in slum areas is more likely to be adversely affected by rainfall as they lack proper access to drainage. Second, reduced consumption of food items at home at endline (due to higher food prices) may also lead to higher malnutrition. High food inflation was recorded across India during this period as a result of production short-falls and high minimum support prices levied by the government (Nair and Eapen, 2012). Food prices rose across India between starting dates of baseline and endline rounds with prices for vegetables increasing by $33 \%$, fruits by $12 \%$ and lentils by $4 \%$. The food index as a whole rose by $7.2 \%$ between the three months (Ministry of Commerce and Industry, 2014).

\subsection{Diet}

In Table 5, the results are from a regression that has the variable food item intake for the child as the dependent variable which is 1 if this item has been consumed at least twice a week on average in the last three months (as reported by the mother). The average baseline consumption of these items in the control group are in the constant term in columns (1) to (4). For example, at baseline, $75 \%$ of the households have green vegetables at least twice a week but only $12.8 \%$ have sweets twice a week. We observe that on average there is no significant impact of the recipe treatment on the consumption of green vegetables or sweets for both the recipe and spillover groups. However, there is a significant increase in porridge consumption in the recipe and spillover groups relative to the control group indicating externalities on behavior. This is consistent with learning spillovers as porridge was the first recipe in the recipe book and there was an increase in the knowledge from the recipe book. Results remain robust to alternative definitions of frequency of dietary items consumed as well as using a probit model and these are available upon request. 
We also find that for eggs and sweets there is significant drop in bi-weekly consumption in all groups. This can be partly explained by the rainfall season and the related environment, partly by the increase in food prices and additionally, there could have been changes in consumption as the month of April coincides with the harvest month in Punjab and there would have been an increase in seasonal consumption. Gupta (2006) notes that the April-June and October-December periods coincide with either the period of major festivals or with the auspicious months of wedding season. Nevertheless, we find that for porridge, there is a decline in consumption in the control group but an increase in the treatment and spillover groups relative to the control group and the in- crease is of a similar magnitude as the decrease in the control group. This implies that seasonality has no negative impact on consumption of porridge in the recipe and spillover groups and part of the reason could be that the recipe book's first recipe was a special costeffective porridge that had wheat, lentils, milk, sugar and oil as ingredients. A 100 gram recipe of this porridge has 310 kilocalories, 6.5 grams of protein, 1.5 grams of iron, and 497 micrograms of carotene, making it not only calorific but also nutritious. At endline, recipe treatment mothers were asked how many times they cooked each recipe. The responses suggested that the three most popular recipes from the book were Suji Halwa (traditional Indian dessert), Rice-Lentil gruel and Porridge.

There appears to be a greater difference between the two groups in increasing traditional sweet intake (higher for recipe group) and porridge (higher for spillover group), but these differences are insignificant. There are three potential explanations for the high porridge coefficient for the spillover group: first, the baseline difference in porridge diet is also higher in the recipe group relative to the spillover group, indicating a catch-up effect. Second, in the spillover group, the proportional increase in porridge consumption from baseline is not higher in magnitude relative to the proportional increase in sweets from baseline in the recipe treatment - there is a 28 percent increase over the baseline for the spillover group compared to a 41 percent increase in sweet consumption for the recipe book. This may suggest substitution between the different diets in the recipe and spillover groups. Third, the substitution between cheap and easy-to-make recipes like porridge and relatively more expensive and more involved recipes such as traditional sweets can be illustrated with how diet changes as a child has more siblings (from Figures A2 and A 3 in the Appendix). Consumption of sweets appears to be falling and consumption of porridge is increasing with an increase in the number of siblings. There does not appear to be a negative effect on other measured dietary items but I cannot test for any effects on the health of other family members. There may be other food items that the mother may be substituting with porridge that are not captured in our analysis. 


\subsection{Food expenditure}

The average household weekly food expenditure at baseline for the control group is reported to be Rs. 442 (constant term on column 1 of Table 6 , equivalent to $\$ 9.82$ ) on a weekly income of Rs. 949 (\$21). Thus, the share of income reported to be spent on food is close to $47 \%$. As depicted in the conceptual framework (in the Appendix), food expenditure can go down or up depending on whether the negative direct price effect dominates the positive indirect quantity effect. We observe in Table 6 that there was a significant reduction in food expenditure in the recipe and spillover groups relative to the control group. The reduction in weekly food expenditure relative to control is substantial (between Rs. 70 to Rs. 120) when compared to the cost of the recipe book, which was only Rs. 10 (20 cents). This suggests that printing and distribution of such recipe books may be an agent of expanding real budget constraints for the households. The increase in knowledge in the spillover group as well as the recipe treatment lends credibility to this result being at least partly because of the informational transfer from the recipe book. It implies that it is not imitation of their neighbors that is driving the result in the spillover group but strong learning and behavioral spillovers. For a more detailed analysis of the food expenditure results, please see the appendix.

\section{Heterogeneity}

The full heterogeneity specification for finding learning and spillover effects on literate mothers is as follows:

$$
q_{i j t}=\alpha_{0}+\alpha_{1}(\text { post })_{t}+\sum_{k} \delta_{k}\left(\text { treatment }_{k}\right)_{j}+\rho(\text { literate })_{i}+
$$

$\sum_{k} \eta_{k}\left(\text { post } * \text { treatment }_{k}\right)_{j t}+\varphi(\text { post } * \text { literate })_{i t}+\sum_{k} \theta_{k}$ (literate $*$

treatment $\left._{k}\right)_{j t}+\sum_{k} \omega_{k}\left(\text { literate } * \text { post } * \text { treatment }_{k}\right)_{i j t}+X_{i j t}+\varepsilon_{i j t}$

As usual, post is a dummy that is 0 for baseline and 1 for endline. The variable treatment $_{k}$ are the individual treatment dummies: recipe and spillover. ${ }^{12}$ The dummy treatment is 1 if the child is in the specific treatment and 0 otherwise. $X_{i j t}$ includes individual and Anganwadi specific controls. To test the hypothesis that the recipe treatment has an impact on knowledge for literate mothers, we need to test if $\eta_{1}+\omega_{1}=0$, where $k=1$ for the recipe treatment.

\subsection{Literate mothers}

It is important to understand how the information spreads to other mothers in the vicinity. In particular, does it depend on whether the mother is literate or not? If it does, then the spillovers may suggest that literate mothers share information only 
with other literate mothers in the slum area or even if they interact with illiterate mothers, these mothers may not be able to retain and apply the information. If it does not, it may mean that information transfer is not restricted to literate mothers. Indeed, this would be of policy relevance, especially because this would imply that printed information can trickle down to even those who cannot read it.

Table 7 provides evidence for the heterogeneous impacts on knowledge and food expenditure of a mother being literate. The direct impact in learning appears to be much greater for literate as compared to illiterate mothers. In the spillover group, learning takes place to a similar degree for both literate and illiterate mothers. A literate mother's quiz score is significantly higher relative to an illiterate mother if she is in the recipe treatment but not if she is in the spillover group. This implies that the nutritional knowledge increase happens on average for both literate and illiterate mothers in the spillover group. The sum of the coefficients on Post*Recipe and Mother can read*Post*Recipe is significantly different from 0 for quiz score at the 1 percent significance level. However, informational spillovers on learning of same-slum dwelling mothers are not restricted to them being literate. This suggests that social networking among mothers in the same slum matters and information is transferred through verbal communication. There could be two channels of informational transfer. First, illiterate mothers may ask neighboring literate mothers or their Anganwadi worker to read out recipes. Second, literate mothers may share information with both literate and illiterate mothers. I find some evidence for the first channel to be active as the informational increase in the recipe treatment is 0.82 points for illiterate but 1.78 points for literate mothers in the quiz. Moreover, it appears not to go through the worker but through literate mothers because there is no differential increase in communication between the worker and the illiterate mother receiving the treatment. But, the second channel is clearly demonstrated by an increase in the quiz score of the spillover mothers regardless of them being literate.

A literate mother at home matters for both knowledge and health, but is in contrast to having a literate father at home as shown in Table A4. There are very small increases in quiz scores for treated mothers if fathers are literate, which may indicate the presence of transaction costs within a household that prohibit informational transfer either because the literate father does not read to the mother (who also cooks the food) or the illiterate mother does not seek his advice or if there is transfer, then she is unable to retain what she is taught because of lower retentive capacity for information. The latter channel is unlikely given that there appear to be informational spillovers from literate to illiterate mothers within a slum. Social networks within slum clusters seem to be responsible for the 0.82 point increase observed for illiterate treated mothers.

In line with the above results, we find that food expenditure is reduced across the board for literate and illiterate mothers in the spillover group, but there 
is a premium in the recipe treatment of being literate in improving quiz scores. Thus, nutritional information campaigns may have differential direct effects for literate mothers increasing the knowledge gap between the literate and the illiterate in the treated group. There is reinforcing evidence of greater heterogeneity in direct effects of the recipe treatment on health, quiz scores and food expenditures in households owning greater proportion of kitchen assets as opposed to non-kitchen assets. This is shown in Tables A5 and A6 (in the Appendix). The results can explain why mothers who switch to lower-cost recipes such as porridge from eggs and vegetables may not be able to improve health of their children if they lack basic kitchen technology such as a fridge, filter, water tap, cooking gas or pressure cooker. As discussed in the Introduction, this is in line with the existing literature on information campaigns. However, spillovers appear to be less heterogeneous in both learning and behavior.

\section{Robustness checks}

\subsection{Clustering}

As the matching happens at the level of a center, the standard errors should be clustered at the level of a center. However, I also run the regressions by clustering standard errors at the level of a slum cluster. This is a more conservative correction as it allows for unobservables to be serially correlated amongst centers within a cluster. The results are robust to clustering at the level of a slum cluster except for the coefficient on intake of porridge which now becomes insignificant. These results are in Panel A of Tables A7, A8 and A9.

\subsection{Differences in observables at baseline}

The control group is quite a bit richer than the treatment/spillover group and this could introduce a bias in our results. We control for income in all our regressions. However, those with higher income could be on a different slope for improving outcomes at endline. To control for this, we interact all control variables with the post dummy and include these in our regression. The results for quiz scores, diet and food expenditure remain robust to their addition as shown in Panel B of Tables A7, A8 and A9.

Next, we carry out Propensity Score Matching tests and are able to match the recipe and spillover groups individually to the control group using our control variables to construct propensity scores. Then we run regressions including the propensity score and its square as well as re- strict the regression to the common support using Dehejia and Wahba (1999). Results for quiz scores, diet and food 
expenditure remain robust to Propensity Score Matching in Tables A10, A11 and A12. In particular, we find increases in the nutritional quiz score related to the recipe book for both the treatment and spillover group, an increase in the consumption of porridge (low-cost recipe) and a reduction in food expenditures.

\subsection{Food prices and income shocks}

We also collected endline prices of major food items (wheat, sugar, eggs, tomato, and laddoo (traditional Indian sweet)) in all slum clusters in Chandigarh. In Table A13, we carry out a Mann-Whitney test to check if the set of prices are significantly different in the treatment/spillover and control groups. The "ranksum" function tests the hypothesis that two independent samples are from populations with the same distribution using the Wilcoxon rank-sum test, also known as the MannWhitney two-sample statistic, as in Wilcoxon (1945) and Mann and Whitney (1947). Reassuringly, we cannot reject the null hypothesis of no differences across these groups. Finally, if there are differential economic shocks in the treatment and control blocks, it may lead us to erroneously attribute the impacts on outcomes to the recipe treatment. To check if incomes grew differentially across the groups, we run a difference-in-difference regression taking income as an independent variable. Table A14 shows that although nominal incomes increased significantly in all groups, there were no differential income shocks in the treatment or spillover groups relative to the control.

\section{Policy implications and conclusion}

I carry out a controlled experiment in urban slums of Chandigarh, India covering a panel of 2632 children and find the presence of positive inter-household spillovers in learning and also on behavior. This paper provides one of the first pieces of evidence on how spillovers in both learning and behavior can take place as a result of an informational campaign. The information campaign is found to be effective in improving knowledge and there is evidence of strong externalities on learning and behavior for other households within the same slum cluster. In particular, the quiz score of neighboring mothers increases. The increase in the quiz score is significant and is driven by the component of the quiz directly related to the recipe book. There are also greater externalities associated with the diet quantity score as opposed to the diet quality score. Spillovers are found on the self-reported intake of porridge, which improves without any observable decline in other foods relative to control. These spillovers may also counteract the adverse effects of seasonality. ${ }^{13}$

The recipe book cost is $\$ 0.22$ per mother per year. Even if there are no positive (or negative) observable effects on health, the expenditure on food is 
reduced due to switching towards lower-cost recipes. Moreover, the reduced expenditure takes place in both directly treated households and those in the spillover region. This implies that households have more income to save and spend on other goods. Taking a lower estimate of weekly saving of Rs. $70(\$ 1.55)$ per household, the recipe book is very cost effective. Its benefit-cost ratio for a household is 7 for every week the households report lower expenditures and if may be closer to 30 on a monthly basis. These are the direct effects without taking into account spillovers. Incorporating spillovers, the benefit-cost ratio should be multiplied by a factor of 1.63 as 61 percent of the sample is directly treated. This implies policy makers in India can help households with young children and their neighbors save more by providing recipe books.

In response to the recipe treatment, households may exhibit greater knowledge, but there are unlikely to be significant health consequences for children, especially for mothers who lack kitchen assets. Thus, providing nutritional information and subsidizing kitchen assets for low-income households may work as complements in reducing malnutrition. ${ }^{14}$ Although, there is no direct impact of nutritional knowledge on health outcomes, this is possible because of several reasons. First, children may be old enough already (3-6 years) for there to be a direct impact on health. Second, a recipe book may have an impact on other dimensions of health behavior that is difficult to capture. Theoretically, it was ambiguous whether the spillovers would be possible for uneducated mothers but evidence seems to suggest that these are possible because of oral trans- mission of information. It was also ambiguous whether the knowledge increase because of the recipe book would translate to greater out-of-book knowledge. This does not appear to be the case. The treatment and its spillovers do have an impact on increasing knowledge, improving nutritional behavior, and reducing food expenditure without worsening child health, so it is still potentially Pareto improving and welfare enhancing and this would not have been obvious without an experiment.

Health interventions often have unintended consequences on those not directly targeted. However, little is known about the spillovers associated with nutritional information campaigns. Detecting the extent and kind of externalities is not only relevant for shaping public health policy in populated urban areas in developing countries, but also for assuming control groups in randomized experiments. For instance, if the control group is taken to be untreated mothers in the same cluster, it would have given us a biased impact of the recipe treatment. Furthermore, mechanisms of diffusion are even less well understood. Whether the externalities are driven through imitation or learning may have different policy implications. Longer-term policies should try and encourage spillovers through learning for the same cost. The spillovers also suggest that randomly assigning a treatment and control across Anganwadis without taking into account the possibility of spillovers within clusters may contaminate the control group biasing 
results even though a randomized controlled experiment is taken to be the gold standard in development economics.

Spillovers in learning and behavior are likely to be an important source of the cost-effectiveness of nutritional campaigns and the determinants of such spillovers may include both environmental and behavioral factors as well as their interaction. In the present context, spillovers cross the literacy barrier and thus, assist in reducing the informational gap that is exacerbated between the literate and the illiterate as a result of the informational treatment. 


\section{References}

Brown, K. H., Black, R. E., \& Becker, S. (1982). Seasonal changes in nutritional status and the prevalence of malnutrition in a longitudinal study of young children in rural Bangladesh. The American Journal of Clinical Nutrition, 36(2), 303-313.

Chaudhuri, A. (2009). Spillover Impacts of a Reproductive Health Program on Elderly Women in Rural Bangladesh. Journal of Family and Economic Issues, 30(2), 113-125.

Onis, M., \& Blössner, M. (2003). The World Health Organization Global Database on Child Growth and Malnutrition: methodology and applications. International Journal of Epidemiology, 32(4), 518-526.

Deaton, A., \& Dreze, J. (2008). Nutrition in India: Facts and Interpretations (Working Paper 1071). Princeton, NJ: Princeton University.

Dehejia, R.,\& Wahba, S. (1999). Causal Effects in Nonexperimental Studies: Reevaluating the Evaluation of Training Programs. Journal of the American Statistical Association, 94(448), 1053-1062.

Deri, C. (2005). Social networks and health service utilization. Journal of Health Economics, 24, 1076-1107.

DHS India, 2005-06. (2007). Final Report, International Institute for Population Sciences (IIPS) and Macro International Inc. Calverton, Maryland, USA.

Duflo, E., \& Saez, E. (2003). The Role of Information And Social Interactions In Retirement Plan Decisions: Evidence From A Randomized Experiment. Quarterly Journal of Economics, 118(August), 815-842.

Duflo, E., Kremer, M., \& Robinson, J. (2007). Why are Farmers Not Using Fertilizer: Evidence from Field Experiments in Kenya. Working Paper . Cambridge, MA: MIT.

Fishman, S. M., Caulfield, L. E., Onis, M.D., Blossner, M., Mullany, L., \& Black, R. E. (2009). "Malnutrition and the global burden of disease: underweight," In: Comparative quantification of health risks: the global and regional burden of disease due to 25 selected major risk factors. Cambridge, MA: World Health Organization/Harvard University Press.

Food and Nutrition Board. (2008). Nutritious Recipes for Complementary Feeding of Young Children. Ministry of Women and Child Development, Government of India.

Godlonton, S., \& Thornton, R. (2012). Peer effects in learning HIV results. Journal of Development Economics, 97(1), 118-129. 
Gragnolati, M., Shekar, M., Gupta, M. D., Bredenkamp, C., \& Lee, Y. K. (2005). India's Undernourished Children: A Call for Reform and Action. HNP World Bank Discussion Paper. Retrieved from http://siteresources.worldbank.org/SOUTHASIAEXT/Resources/2235461147272668285/IndiaUndernourishedChildrenFinal.pdf

Gupta, P. (2006). Macroeconomic Determinants of Remittances: Evidence from India. Economic and Political Weekly, 41(26), 2769-2775.

Hsieh, C. R., Yen, L. L., Liu, J. T., \& Lin, C. J. (1994). Smoking, health knowledge, and anti-smoking campaigns: An empirical study in Taiwan. Journal of Health Economics, 15, 87-104.

Hungama Report, (2011). Fighting Hunger and Malnutrition. Retrieved from http://motherchildnutrition.org/resources/pdf/HungamaBKDec11LR.pdf

Imbens, G. W., \& Rubin, D. B. (1997). Bayesian Inference for Causal Effects in Randomized Experiments with Noncompliance. Annals of Statistics, 25(1), 305-327.

Imbens, G.W., Wooldridge, J.M., (2009). Recent Developments in the Econometrics of Program Evaluation. Journal of Economic Literature 47, 5--86. doi:10.1257/jel.47.1.5

Jensen, R. (2010). The (Perceived) Returns to Education and the Demand for Schooling. Quarterly Journal of Economics, 125(2), 515-548. doi: 10.1162.

Jorgenson, A. \& Rice, J. (2012). Urban Slums and Children's Health in Less-Developed Countries. Journal of World-Systems Research, 18(1), 103-116.

Karthikeyan, R., \& Nedunchezhian, V. R. (2014). An analysis of price trends and its behavioral patterns of the Indian poultry market with reference to egg. African Journal of Agricultural Research, 9(1), 8-13.

Kobayashi, M. [Masako]., \& Kobayashi, M. [Maiko]. (2006). The relationship between obesity and seasonal variation in body weight among elementary school children in Tokyo. Economics \& Human Biology, 4(2), 253261.

Kremer, M., \& Miguel, E. (2007). The Illusion of Sustainability. Quarterly Journal of Economics, 122(3), 1007-1065.

Kwak, N. (1999). Revisiting the Knowledge Gap Hypothesis: Education, Motivation, and Media Use. Communication Research, 26, 385-413.

Mann, H. B., \& Whitney, D. R. (1947). On a test whether one of two random variables is stochastically larger than the other. Annals of Mathematical Statistics, $18,50-60$.

Manski, C. F. (1993). Identification of endogenous social effects: the reflection problem. The Review of Economic Studies, 60, 531--542.

Mehta, B., Grover, K., \& Kaur, R. (2013). Nutritional Contribution of Mid Day Meal to Dietary Intake of School Children in Ludhiana District of Punjab. Journal of Nutrition and Food Sciences, 3, 183. 
Miguel, E., \& Kremer, M. (2004). Worms: Identifying Impacts on Education and Health the Presence of Treatment Externalities. Econometrica, 72(1), 159-217.

Miller, J., Brett, R., Tran, C., Sean, B., Lada, C. O., Whetter, K., \& Cobiac, L. (2013). Seasonal variation in the nutritional status of children aged 6 to 60 months in a resettlement village in West Timor. Asia Pacific journal of clinical nutrition, 22(3), 449-456.

Ministry of Commerce and Industry. (2014). Wholesale Price Index (WPI) Data. Government of India. Retrieved from http://www.eaindustry.nic.in.

Ministry of Women and Child Development. (2007). ICDS Guidelines. Government of India. Retrieved from http://wcd.nic.in/sites/default/files/AR200708.pdf.

Nadeau, R., Nevitte, N., Gidengil, E., \& Blais, A. (2008). Election Campaigns as Information Campaigns: Who Learns What and Does it Matter? Political Communication, 25, 229-248.

Nair, S. R., \& Eapen, L. M. (2012). Food Price Inflation in India (2008 to 2010). Economic \& Political Weekly, 47(20), 47.

Oldiges, C. (2012). Cereal consumption and per capita income in India. Economic \& Political Weekly, 47(6), 63.

Oster, E., \& Thornton, R. (2012). Determinants Of Technology Adoption: Peer Effects In Menstrual Cup Take-Up. Journal of the European Economic Association, 10(6), 1263-1293.

Pelletier, D. L., Edward A. Frongillo Jr., Schroeder, D. G., \& Habicht, J. P. (1995). The effects of malnutrition on child mortality in developing countries. Bulletin of the World Health Organization, 73(4), 443-448.

Radhakrishna, R. (2006). Food consumption and nutritional status in India: Emerging trends and perspectives (Indira Gandhi Institute of Development Research, Mumbai Working Paper No. 2006-008). Retrieved from http://www.igidr.ac.in/pdf/publication/WP-2006-008.pdf

Reinikka, R., \& Svensson, J. (2005). Fighting Corruption to Improve Schooling: Evidence from a Newspaper Campaign in Uganda. Journal of the European Economic Association, 3(2-3), 259-267.

Rosenthal, S. S. \& Strange, W. C. (2008). The attenuation of human capital spillovers. Journal of Urban Economics, 64(2), 373-389.

Sen, P. (2005). Of Calories and Things: Reflections on Nutritional Norms, Poverty Lines and Consumption Behavior in India. Economic \& Political Weekly, 40(43), 4611-4618.

Siegel, M., \& Biener, L. (2000). The impact of an antismoking media campaign on progression to established smoking: results of a longitudinal youth study. American Journal of Public Health, 90(3), 380-386. 
Singh, P. (2015). Performance pay and information: Reducing child undernutrition in urban slums. Journal of Economic Behavior \& Organization, 112, 141-163. Retrieved from http://dx.doi.org/10.1016/j.jebo.2015.01.008.

Snyder, L. B. (2007). Health Communication Campaigns and Their Impact on Behavior. Journal of Nutrition Education and Behavior, 39, 32-40.

Speizer, I. S., Tambashe, B. O. \& Tegang, S. P. (2001). An evaluation of the "Entre Nous Jeunes" peer-educator program for adolescents in Cameroon. Studies in Family Planning, 32, 339-351.

Tandon, B.N. (1989). Nutritional Interventions through Primary Health Care: Impact of the ICDS Projects in India. Bulletin of the World Health Organization, 87, 77-80.

Wilcoxon, F. (1945). Individual comparisons by ranking methods. Biometrics, 1, 80-83.

WHO. (1983). Measuring change in nutritional status. Geneva, Switzerland. Retrieved from http://apps.who.int/iris/bitstream/10665/38768/1/9241541660.pdf

WHO. (2006). Child Growth Standards. Geneva, Switzerland. Retrieved from http://www.who.int/childgrowth/en. 


\section{Notes}

${ }^{1}$ The other main role of the child care worker is to allocate mid-day meals to children in the Anganwadi. Tandon (1989) finds that the ICDS nutrition intervention programs led to significant reductions in malnutrition among children in comparison to non-ICDS groups receiving information through other programs.

${ }^{2}$ The literature on the impact of informational campaigns is plagued with self- selection issues (Manski, 1993). Individuals could self-select into network groups based on their characteristics. However, I find the ex-ante observable characteristics of mothers between the different groups to be very similar and there is no migration between the sampled groups. Self-selection of participants within the treated and untreated groups is less of an issue as compliance among mothers is close to 95 percent and similar across all groups.

${ }^{3}$ These checks are conducted every three months and all children present are weighed by a doctor to determine the malnutrition rates in each block.

${ }^{4}$ For selecting the adequate sample size, I used the software, Optimal Design Version 1.77. The number of children per center or $\mathrm{n}$ was taken to be 25 Appendix Figure A5 shows power against intra-class correlation for different size effects. For instance, the intra-class correlation needed to detect a small effect of 0.2 standard deviations at the 5 percent significance level and a power of 0.8 is about 0.05 . If the effect size is slightly larger at $\delta=0.30$, intra-class correlation can be as high as 0.15 and the power would still be sufficiently high.

${ }^{5}$ This was calculated by the local Nutritionist, Food and Nutrition Board (Rs. $4=9$ cents). Figure A1 in the Appendix illustrates a recipe from the book (banana pie).

${ }^{6}$ Enumerators were trained and supervised by me on the ground throughout the experiment. The weighing machines used in both rounds were re-used for the same set of children for accuracy.

${ }^{7}$ Table A1.1 also shows probit results of being attrited on treatment and spillover groups. We find insignificant differences so there appears to be no effect of assignment on attrition.

${ }^{8}$ Assuming $1 \$=$ Rs. 45.

${ }^{9}$ The infrastructure in the Anganwadi centres (blackboard, chart, toilet, drinking water, electricity) are very similar across all groups and wages of workers are identical.

${ }^{10}$ This regression also includes individual dummies for other treatments implemented during the project in another block (incentive $e_{j}$ and combined s $_{j}$ ) as well as their interactions with post: See Singh (2015) for details of these treatments. This 
is a conservative method and results remain very similar if we restrict the regression to only the recipe, spillover and control groups (available upon request).

${ }^{11}$ It is possible that the weight may go up in the long run, and the time horizon of three months is not sufficient to capture spillovers. The window was chosen to coincide with the usual window between health checkups at Anganwadis in Chandigarh which is deemed to be sufficient to observe changes in malnutrition status if children are given a more calorific diet (i.e. mothers prepare one recipe from the book daily, each of which is greater than $300 \mathrm{kcal}$ ). This is based on estimates that $300 \mathrm{kcal}$ additional calories per day is estimated to lead to a $200 \mathrm{~g}$ increase in the body weight of a 4 year old child over a period of 3 months (WHO, 1983). However, it is not surprising that there is no effect on weight even though there are knowledge spillovers because at baseline the correlation between mothers' nutritional knowledge and child's weight is small and insignificant as shown in Appendix Table A15. One issue with using a difference-in-differences analysis is that even if baseline weights in the groups are similar, they may be on different pretrends. For example, if the children in the recipe treatment are growing at a lower rate than the children in the spillover or control group, it may bias downwards our estimates of the direct impact of the recipe treatment by simply looking at difference-in-differences. However, pre-baseline weights (on average 3 months prior to baseline) that were recorded in the Anganwadi registers were also noted in the baseline survey. This helps us check for differential pre-trends in weights. Table A3 in the Appendix provides the results of a placebo check to see if trends were different prior to baseline. The weights of children have increased in the past 3 months (as they have become older), but there are no differential trends for the spillover or the recipe group children relative to control. The placebo test makes our assumption about similar pre-trends more plausible and confirms that the common trends assumption for interpreting diff-in-diff coefficients as causal is valid. Even after one year following the implementation of the treatment, there were no significant effects on child weight in the treatment or spillover groups relative to control. Even though the weight on average increased by 1.68 kilograms, the difference-in-difference coefficients for long-term impacts of the recipe treatment and spillovers are insignificant at the $10 \%$ level, small and negative.

12 Including or excluding the observations from other treatments implemented in the project to a separate block does not make a difference to the interpretation of any of our results. These have been included in the background for improving e ciency but the gains are very minimal and results are extremely robust to only focusing on recipe and spillover groups.

${ }^{13}$ I test for (a) effect of different quantiles of maternal knowledge on child's health, and (b) effect of recipe and spillover treatments on different quantiles of child weight, and find a lack of threshold level effects of knowledge on health or of knowledge (implemented through treatments) on different health thresholds. 
${ }^{14}$ The general equilibrium effects of how such a policy would impact the price of food items is beyond the scope of this paper. 